\title{
The Best Way to Prevent and Treat coronavirus Infections
}

\section{Leonid Tell, MD,PhD}

NE University Institute of Essence Natural, USA, Medical University Astana, Kazakhstan.

*Corresponding Author: Leonid Tell, NE University Institute of Essence Natural, USA. Medical University, Astana, Kazakhstan.
Received: May 22, 2020

Published: July 06, 2020

(C) All rights are reserved by Leonid Tell.

\begin{abstract}
The method goes as follows:

1. Do not attempt to reduce body temperature increase by endo and exogenous pyrogens.

2. Breath hot alkaline vapor on a regular basis.

3. If pneumonia develops, use conventional methods of treatment ,but no use of antipyretics.

4. If there is a need to switch to artificial ventilation for the patient (which would occur rarely considering the rules are followed), then be sure to use hot, humid, alkaline air during ventilation.
\end{abstract}

Keywords: Coronavirus; Exopyrogens; Endopyrogens

The virus does not cause harm as long as it does not invade the cell! Virus penetrates the cell due to its protein-enzymatic shell. This requires certain conditions: a certain temperature no higher than 37-38 degrees Celsius and an acidic environment. Once virus has injected its DNA-RNA into the cell, they multiply quickly, and in greater numbers they come out again to infect other cells. The cell becomes foreign to the body after a virus enters it. And so, at this time, the mechanisms of cellular immunity begins to work, (they always exist), which kill this cell with the virus and at this moment a large number of exopyrogens and endopyrogens are formed. Interestingly, the elevated temperature does not allow the virus to enter the cell and multiply, and moreover, together with the pyrogens, the mechanisms of cellular immunity are activated! All this is described and known in extensive medical literature. And for the formation of humoral immunity, a temperature of 37 Celsius and higher is also good. This mechanism was created by nature. Thus, to stop a virus attack, you need to: maintain a temperature in between 37 and 39 degrees Celsius and maintain an alkaline environment which you can add antioxidants to. It is interesting that after the viral DNARNA multiplies in the cell, in order to transfer them to the lymph- blood, it is also necessary for the temperature to be no higher than 38-39 Celsius and have an acidic environment! The use of antipyretics allows viruses to infect more cells.

Do not be afraid of increased body temperature: this is a sign of a struggle going on in the body, a struggle for health, for the restoration of impaired functions. The severity of an infectious disease does not depend much on the height of the temperature, but rather on the pathogenic effect of the infection on the body. It was noted that the artificial cooling of temperature-sensitive patients with the help of cold baths did nothing but harm. However, the benefits of warming the patient in a steam bath at the onset of a cold have long been noticed (not at the height of a febrile reaction). The body temperature in the sauna can increase by $1-2.5$ degrees.

In the experiment, it was found that preliminary mild physical overheating or a rise in temperature with pyrogens makes the animal insensitive to lethal doses of arsenic and curare - the antitoxic function of the liver increases. Pre-heating of the animal organism also facilitated the course of anthrax, damage to streptococci, 
staphylococci. Conversely, when the rabbits were not allowed to develop a temperature reaction by administering antipyretics, the paratyphoid fever developed more severely than in animals with an elevated temperature (PT).

The adaptive role of raising temperature has a lot of evidence. When discussing the adaptive role of PT, a significant question arises: does a high body temperature have a detrimental effect on microorganisms? The development of germs and viruses is very dependent on temperature. The optimum temperature for viruses is $35^{\circ} \mathrm{C}$. Viruses multiply much worse at $37^{\circ} \mathrm{C}$ and at $39-40^{\circ} \mathrm{C}$ the viruses stop multiplying and die. Because, on the one hand, high temperature enhances the formation of interferon in the cells infected with the virus, which inhibits the reproduction of the virus, and on the other, the cellular immunity of the fight and defense of the body is activated. The maximum antiviral activity of interferon appears at $38-39.5^{\circ} \mathrm{C}$. Microorganisms come into contact with cells that kill and absorb them (cellular immunity). At the same time, substances called pyrogens are released from dead microbes, viruses, and dead cells of humoral immunity. They act on the temperature control center in the brain causing an increase in temperature. Interestingly, when meeting with microorganisms, the body cells begin to secrete such pyrogen substances. And fever and pyrogens organize the recovery of the body. It turns out that microorganisms on the one hand carry the disease, and on the other activate the mechanisms of recovery. It is perhaps difficult to find substances with such high activity and such a large variety of effects such as pyrogens. In addition to increasing temperature, pyrogens have the following properties:

1. Enhance the formation of specific antibodies.

2. Increase non-specific bactericidal properties of blood.

3. Stimulate the development of white blood cells, increasing their number in the blood.

4. Increase the phagocytic activity of leukocytes.

5. Strengthen important protective and adaptive functions as detoxification, phagocytosis, immunogenesis.

6. Increase the permeability of tissue barriers and increase the concentration of drugs used in organs such as sulfonamides, antibiotics.

7. Are strong stressors: they significantly enhance the secretion of corticotropin, which stimulates the formation of adrenal glucocorticoids. Thus, the general non-specific resistance (resistance) of the body increases.
8. Pyrogens, acting on the center of thermoregulation, increase the tone of peripheral superficial vessels, while blood vessels in the internal organs increase.

9. Pyrogens have a small stimulating effect on the central nervous system.

10. Pyrogens cause shifts in the pituitary-adrenal gland system: increases the release of adrenocorticotropic hormone (ACTH), increases the release of growth hormone (STH), increases the release of adrenaline and norepinephrine by the adrenal glands.

11. Pyrogens cause shifts in the cardiovascular system: peripheral resistance decreases and blood circulation in the internal organs accelerates by 2 - 3 times compared to the original.

12. Activate fibrinolytic (dissolving blood clots) blood activity.

13. Tumor-killing effect of pyrogens is noted.

14. In experiments, it was noted that pyrogens inhibit the formation of peptic ulcers of the stomach.

15. Pyrogens affect dense scar tissue: scars soften, scar tissue is replaced by normal.

16. Pyrogens stimulate neuroregenerative processes of restoration of nervous tissue after damage.

17. The antitoxic function of the liver is enhanced.

There is a treatment method - pyrotherapy, in which a person is purposefully injected with substances that increase body temperature - pyrogens. The rise in body temperature is the main manifestation of the action of pyrogens, from which their name arose - "giving birth to heat".

Serve as the basis for their use as drugs. At the same time, pay attention - everything is in microdoses!

All these versatile manifestations of the action of pyrogens are not the main essence of elevated body temperature, but are its important companions. Why, then, patients, and often doctors, with any, even a slight rise in temperature, tend to use an antipyretic medicine instead? The fact is that subjective sensations at an elevated temperature are unpleasant. Often a febrile illness is accompanied by headache, muscle pain, aching joints. Antipyretic drugs have analgesic properties, and this attracts the patient and the doctor to them. These drugs also stimulate the secretion of corticosteroids, which in certain quantities increase the nonspecific resistance of the body. 
However, these positive aspects of the action of antipyretic drugs in some cases can become secondary in comparison with the harmful effect of the inability to maintain elevated temperatures. That is, both the doctor and the patient, who always strive to "bring down" the fever by any means, are wrong in doing so.

In recent years, it has been found that suppressing the synthesis of prostaglandin E by antipyretic can reject synthetic processes to enhance the production of leukotrienes, which can cause an adverse side reaction - asthma-like conditions and other allergic manifestations. The question is pertinent: what if the condition is so severe and the temperature is so high that you can't do without drugs? In this regard, the answer is clear: we do not recommend a complete refusal, but the use of medications should be reasonable. However, it is worth pondering: why does the disease proceed in such a severe form? After all, this is a consequence of the insufficient nonspecific resistance of the body to the pathogen, it is a consequence of the fact that the body is weakened... as a result of which, we believe, it is clear. Another aspect related to colds and viral diseases. You are sick and your appetite is gone. The sick person doesn't want to eat, but he is afraid: "how can you eat without food?" Where are the calories for the cells? "We unequivocally suggest giving up food for 1 - 2 days. This is a completely unresolved physiology issue, but one thing is clear - the sick body does not want to eat.

But you need to use a lot of fluids, water - as an important healing tool. We also recommend that you do not stop dousing with cold water for viral diseases. For that insignificant period of time, when you shower, take a shower, you will not get too cold. Quite the contrary, with a certain feeling of cold, the temperature of the deep parts of your body will even increase, which plays a significant role in stimulating the body's defenses:

1. Take a very cold shower every morning.

2. Drink a lot of liquid.

3. If you suddenly have a fever, do not take antipyretics in any case, it is better not to take anything at all.

4. As little as possible to be in a room where there is air conditioning!!!

5. If possible, visit the sauna (bath and steam room) more often.

6. Rarely have a sweet food.
7. More and more movements. Don't close fitness clubs that have sauna, stim room.

8. Do breathing exercises and exercise for up to 2 hours a day.

9. Use of products for production of surfactants.

10. Garlic, onion, ginger and Bapol are use to increase immunity. And eat right.

11. If necessary, for bacterial complications, according to the doctor's decision, you can and sometimes you need to take antibiotics or other antibacterial drugs-for example, Biseptol.

12. For prevention in the period of the outbreak, and even more for treatment, you need to breathe hot steam. To do this, you need to have Stim inhalers. They can be very simple or complex structures. In the water from which steam is made, you need to add soda, eucalyptus and any other antiseptics.

13. Breathing steam inhalers are much more necessary than respiratory ventilator. Artificial ventilation of the lungs sometimes aggravates the patient's condition. Or if artificial ventilation is carried out, it should be with hot, humid air.

\section{Assets from publication with us}

- Prompt Acknowledgement after receiving the article

- Thorough Double blinded peer review

- Rapid Publication

- Issue of Publication Certificate

- High visibility of your Published work

Website: www.actascientific.com/

Submit Article: www.actascientific.com/submission.php Email us: editor@actascientific.com

Contact us: +919182824667 